\title{
CEREBRAL EFFECTS OF COLD REPERFUSION AFTER HYPOTHERMIC CIRCULATORY ARREST
}

Marek P. Ehrlich, MD

Jock McCullough, MD

David Wolfe, MD

Ning Zhang, MD

Howard Shiang, DVM

Donald Weisz, $\mathrm{PhD}^{\mathrm{b}}$

Carol Bodian, DrPH ${ }^{\mathrm{c}}$

Randall B. Griepp, MD
Objectives: This study was undertaken to explore whether an interval of cold reperfusion can improve cerebral outcome after prolonged hypothermic circulatory arrest.

Methods: Sixteen pigs $(27-30 \mathrm{~kg})$ underwent 90 minutes of circulatory arrest at a brain temperature of $20^{\circ} \mathrm{C}$. Eight animals were rewarmed immediately after hypothermic circulatory arrest (controls), and 8 were reperfused for 20 minutes at $20^{\circ} \mathrm{C}$ and then rewarmed (cold reperfusion). Electrophysiologic recordings, fluorescent microsphere determinations of cerebral blood flow, calculations of cerebral oxygen consumption, and direct measurements of intracranial pressure (millimeters of mercury) were obtained at baseline $\left(37^{\circ} \mathrm{C}\right)$, before hypothermic circulatory arrest, after discontinuing circulatory arrest at $37^{\circ} \mathrm{C}$ deep brain temperature, and at 2, 4, and 6 hours thereafter. Histopathologic features and percent brain water were determined after the animals were sacrificed.

Results: Cerebral blood flow and oxygen consumption decreased during cooling: cerebral oxygen consumption returned to baseline levels after 4 hours, but cerebral blood flow remained depressed until 6 hours in both groups. Cold reperfusion failed to improve electrophysiologic recovery or to reduce brain weight, but median intracranial pressure increased significantly less after cold reperfusion than in controls $(P=.02)$. Although no significant difference in the incidence of histopathologic abnormalities between groups was found, all 3 animals with an intracranial pressure of more than $15 \mathrm{~mm} \mathrm{Hg}$ after immediate rewarming had histopathologic lesions, and high intracranial pressure was more prevalent among all animals with subsequent histopathologic lesions $(P=.03)$.

Conclusions: Cold reperfusion significantly inhibited the rise in intracranial pressure seen in control pigs after 90 minutes of circulatory arrest at $20^{\circ} \mathrm{C}$, suggesting that cold reperfusion may decrease cerebral edema and thereby improve outcome after prolonged hypothermic circulatory arrest. (J Thorac Cardiovasc Surg 2001;121:923-31)
$T^{\text {he }}$ he use of profound hypothermic circulatory arrest (HCA) has become common practice in the repair of a variety of cardiovascular abnormalities. Nevertheless, concern persists about the efficacy of this technique in

From the Departments of Cardiothoracic Surgery, Pathology, ${ }^{a}$ Neurosurgery, ${ }^{\mathrm{b}}$ and Biomathematics ${ }^{\mathrm{c}}$ Mount Sinai School of Medicine, New York, NY.

This work was supported by grant HL 45636 from the National Institutes of Health and by the Nat Lapkin Foundation.

Read at the Eightieth Annual Meeting of The American Association for Thoracic Surgery, Toronto, Ontario, Canada, April 30-May 3, 2000.

Copyright (C) 2001 by The American Association for Thoracic Surgery

0022-5223/2001 $\$ 35.00+0 \quad \mathbf{1 2 / 6 / 1 1 3 1 7 5}$

doi:10.1067/mtc.2001.113175 protecting the brain, especially when longer durations of HCA are expected. The mechanism of cerebral injury after HCA remains unclear, however, and the extent to which postischemic cerebral damage is affected by events during reperfusion is not known. This study was undertaken to examine whether a short interval of cold reperfusion could improve cerebral outcome after HCA.

The idea that cold reperfusion might improve cerebral recovery has some intrinsic theoretical appeal. The hypothesis that this modification in the technique of implementing HCA might be beneficial was reinforced by the independent observations of 2 investigators studying cerebral blood flow (CBF) after HCA in infants and children recovering from operations to correct congenital heart defects: both reported that the velocity of flow in the middle cerebral artery measured by transcranial 
Doppler techniques was much better postoperatively in patients in whom rewarming was preceded by an interval of cold reperfusion after HCA. ${ }^{1,2}$ A subsequent clinical study confirmed the beneficial effect of delayed rewarming on postoperative $\mathrm{CBF}$ in infants after HCA, but no systematic study of its impact on postoperative cerebral physiology or on the occurrence of cerebral injury has previously been conducted. ${ }^{3}$

\section{Materials and methods}

Sixteen juvenile Yorkshire pigs (Thomas D. Morris Inc, Reisterstown, Md), 3 to 4 months of age, weighing 27 to 30 $\mathrm{kg}$, were assigned to 1 of 2 groups after 90 minutes of HCA at $20^{\circ} \mathrm{C}$ : control $(n=8)$, in which standard rewarming was begun immediately, or cold reperfusion $(n=8)$, in which rewarming was preceded by an interval of cold reperfusion.

Preoperative management. All animals received humane care in accordance with the "Principles of Laboratory Animal Care" formulated by the National Society for Medical Research and the "Guide for the Care and Use of Laboratory Animals" prepared by the Institute of Laboratory Animal Resources, National Research Council, and published by the National Academy Press, revised 1996. The protocol for these experiments was approved by the Mount Sinai Institutional Animal Care and Use Committee.

Anesthesia and hemodynamic monitoring. Anesthesia was induced with ketamine hydrochloride $(10 \mathrm{mg} / \mathrm{kg}$ intramuscularly) and muscular paralysis was maintained with pancuronium $(0.1 \mathrm{mg} / \mathrm{kg}$ intravenously). After endotracheal intubation, the animals were maintained on positive-pressure ventilation with $100 \%$ oxygen; anesthesia was maintained with isoflurane (1\%). Appropriate catheters were positioned in the femoral artery and vein to allow sampling and pressure monitoring, in the pulmonary artery for determination of cardiac output, in the esophagus and rectum for temperature determinations, and in the bladder to monitor urine output. Sagittal sinus cannulation was undertaken as previously described, and epidural as well as deep brain temperatures were also monitored. ${ }^{*}$ Systemic arterial, venous, and sagittal sinus blood samples were obtained to determine $\mathrm{pH}, \mathrm{Po}_{2}, \mathrm{PCO}_{2}$, oxygen saturation, oxygen content, hematocrit value, and hemoglobin concentration (Ciba-Corning Diagnostic Corp, Medfield, Mass). Glucose and lactate were analyzed with a YSI 2300 Stat device (Yellow Springs Instrument Co, Yellow Springs, Ohio). Temperatures were recorded at intervals throughout the study.

CBF and cerebral metabolism. CBF was measured with fluorescent microspheres as described by us in previous studies (unpublished data). In brief, approximately 0.8 to $1.2 \times$ $10^{6}$ microspheres $15 \pm 0.5 \mathrm{\gamma m}$ in diameter in 6 different colors were injected and flushed with $5 \mathrm{~mL}$ of saline solution into a left ventricular catheter before and after cardiopulmonary bypass $(\mathrm{CPB})$ and into the arterial cannula during

*Ehrlich MP, McCullough JN, Juvonen T, Zhang N, Weisz DJ, Bodian CA, et al. Effect of hypothermia on cerebral blood flow and metabolism in the pig. Unpublished data.
CPB. Blood reference samples were withdrawn from the femoral arterial line at a constant rate $(2.91 \mathrm{~mL} / \mathrm{min})$ with a Harvard withdrawal pump (Harvard Bioscience, Inc, Holliston, Mass) beginning 10 seconds before microsphere injection and ending 110 seconds after injection. After the last microsphere injection 6 hours after rewarming, the animals were killed with sodium pentobarbital $(30 \mathrm{mg} / \mathrm{kg})$ and potassium chloride $(6 \mathrm{mEq} / \mathrm{kg})$. In all 16 animals, the brain was removed, the 2 hemispheres cut in the middle, and the specimens were weighed. Fluorescent analysis was carried out by flow cytometry (IMT, Neuchâtel, Switzerland).

CBF was calculated by the following equation:

$\mathrm{CBF}(\mathrm{mL} / 100 \mathrm{~g} / \mathrm{min})=($ Cerebral tissue counts

$\times$ Rate of withdrawal) (100/(Counts in reference sample $\times$ Brain weight)

Sagittal sinus and arterial samples were obtained simultaneously for calculation of cerebral oxygen extraction (arteriovenous oxygen content difference).

Cerebral metabolic rate of oxygen $\left(\mathrm{CMRO}_{2}\right)$ was determined as follows:

$$
\begin{gathered}
\mathrm{CMRO}_{2}(\mathrm{~mL} / 100 \mathrm{~g} / \mathrm{min})=\mathrm{CBF}\left(\text { Arterial } \mathrm{O}_{2}\right. \\
\text { content } \left.- \text { Sagittal sinus } \mathrm{O}_{2} \text { content }\right) / 100
\end{gathered}
$$

Measurement of intracranial pressure. Intracranial pressure (ICP) was measured with a standard clinical transducer that consists of a miniature strain gauge pressure sensor mounted in a titanium case at the tip of a $100-\mathrm{cm}$ flexible nylon tube (Codman; Johnson \& Johnson, New Brunswick, NJ). The microsensor monitors ICP directly in the brain parenchyma, which was accessed via the incision used for sagittal sinus cannulation.

Measurement of percent brain water. An attempt was made to assess the severity of cerebral edema by determining the ratio of wet weight to total brain weight. The right hemisphere of each brain was weighed on removal and then was desiccated in an oven at $80^{\circ} \mathrm{C}$ and reweighed daily until no further reduction in weight was noted on successive measurements. The percent brain water was calculated as $100 \times$ (Total brain weight - Dry weight)/Total brain weight.

Electroencephalography and evoked potential monitoring. Cortical electrical activity was monitored from 4 stainless steel screw electrodes implanted in the skull, as previously described in detail, and processed as in earlier studies. ${ }^{4}$ Continuous electroencephalographic (EEG) activity was recorded for 3 minutes at the time of each measurement. Somatosensory evoked potentials were recorded from the cervical spine and bilateral skull sites in response to stimulation of the median nerve, as described in detail in earlier studies, and their amplitudes were reported as a percent of baseline recordings.

CPB. Through a right thoracotomy in the fourth intercostal space, the heart and great vessels were exposed. After heparinization $(300 \mathrm{IU} / \mathrm{kg}$ ), the ascending aorta was cannulated with a $16 \mathrm{~F}$ arterial cannula and the right atrial appendage with a single $24 \mathrm{~F}$ atrial cannula, and nonpulsatile CPB was initiated at a flow rate $100 \mathrm{~mL} \cdot \mathrm{kg}^{-1} \cdot \mathrm{min}^{-1}$. A cannula was passed from the right superior pulmonary vein into 
the left ventricle to permit the decompression of the left side of the heart during CPB. A heat exchanger was used for core cooling, and surface cooling was achieved with a cooling blanket. A membrane oxygenator (VPCML Plus; Cobe Laboratories Inc, Lakewood, Colo) was primed with $1 \mathrm{~L}$ of $0.9 \%$ sodium chloride, 1 unit of $5 \%$ albumin, furosemide (1 $\mathrm{mg} / \mathrm{kg}$ ), heparin (5000 IU), and potassium chloride (1 $\mathrm{mEq} / \mathrm{kg}$ ). The $\mathrm{pH}$ was maintained, by means of alpha-stat principles, at 7.40 with an arterial $\mathrm{PCO}_{2}$ of 35 to $40 \mathrm{~mm} \mathrm{Hg}$, uncorrected for temperature.

$\mathrm{CPB}$ with perfusion cooling was carried out for 45 minutes to attain a deep brain temperature of $20^{\circ} \mathrm{C}$. Cardiac arrest was induced by adding potassium chloride $(1 \mathrm{mEq} / \mathrm{kg})$ to the perfusate, and topical cardiac cooling was then begun and maintained throughout the procedure. The ascending aorta was crossclamped just proximal to the aortic cannula.

Experimental protocol. After aortic crossclamping, all 16 animals underwent a 90-minute interval of HCA. After this period, 8 animals were immediately begun on the standard rewarming protocol-in which the blood is kept within $10^{\circ} \mathrm{C}$ of body temperature and its temperature is never raised above $37^{\circ} \mathrm{C}$ - until a deep brain temperature of $37^{\circ} \mathrm{C}$ was reached. $\mathrm{CPB}$ was discontinued in this group approximately 60 minutes after the beginning of reperfusion. The other 8 animals were reperfused for the first 20 minutes at $20^{\circ} \mathrm{C}$ with flow rates to achieve a mean blood pressure of $50 \mathrm{~mm} \mathrm{Hg}$ before rewarming was initiated; CPB in the cold reperfusion group was discontinued approximately 80 minutes after the start of reperfusion. All animals were weaned with cardiac support provided by dobutamine and with administration of furosemide (100 mg), mannitol (12.5 g), and hydrocortisone (40 mg).

During the experiments, hemodynamic, metabolic, and electrophysiologic measurements were recorded at 6 different times:

1. At baseline: $37^{\circ} \mathrm{C}$ deep brain temperature

2. At the end of cooling, at $20^{\circ} \mathrm{C}$, immediately before institution of HCA

3. After discontinuing $\mathrm{HCA}$, at $37^{\circ} \mathrm{C}$ deep brain temperature (approximately 1 hour after the start of reperfusion)

4. Two hours after the start of reperfusion

5. Four hours after the start of reperfusion

6. Six hours after the start of reperfusion

Histopathologic analysis. After fixation, the brain was examined grossly and the cerebrum was sectioned as previously described. ${ }^{5}$ Sections were then processed into paraffin, and $5-\mu \mathrm{m}$ sections were stained with hematoxylin and eosin. Alternate coronal sections of the left hemisphere of each animal were systematically examined by a single experienced senior neuropathologist (D.W.), who was blinded both to the experimental design and to the identity and fate of individual animals. He carefully screened each section for the presence or absence of any infarctive or other damage.

Definition of the anatomic regions scored was as previously described in detail. Morphometric analysis of the volume of ischemic injury of the cortex was classified into 5 groups as follows:

$0=$ No microscopic ischemic damage identified in any sections
$1=$ Less than $5 \%$ of total neocortex infarcted

$2=$ More than $5 \%$ but less than $30 \%$ of total neocortex infarcted

$3=$ More than $30 \%$ but less than $80 \%$ of total neocortex infarcted

$4=$ More than $80 \%$ of total neocortex infarcted

Statistical analysis. Data are shown as mean and standard deviation, except for the electrophysiology variables, which are given as median and range. Differences between groups at baseline were tested by $t$ tests or Wilcoxon signed rank tests, as appropriate. The Wilcoxon test was also used for differences between groups in the electrophysiology data. Differences between groups in all other variables were tested by a repeated-measures analysis of variance, using Proc Mixed in SAS (SAS Institute, Inc, Cary, NC), with an unstructured covariance matrix.

\section{Results}

\section{Physiologic data}

Comparability of experimental groups. The median weight of the animals in the control group was $29 \mathrm{~kg}$ (29-31 kg) and in the cold reperfusion group $30 \mathrm{~kg}$ (29$31 \mathrm{~kg})(P=.15$ by exact Wilcoxon test). The median CPB cooling time in the control group was 44.5 minutes (43-45 minutes), compared with 45 minutes (4446 minutes) in the cold reperfusion group $(P=.31$ by exact Wilcoxon test). Although there were statistically significant differences in esophageal and rectal temperature between groups, there were no differences in epidural temperatures (Table I). Most important, deep brain temperature measurements (Fig 1) showed no statistically significant difference between the 2 groups.

Hemodynamic data. All animals were in stable condition before, during, and after CPB, although cardiac output fell significantly in both groups with cooling and remained below baseline levels even 4 hours after the start of rewarming. There was a statistically significant difference between groups, but that was due to differences in the baseline values; average differences between groups in regard to changes from baseline did not differ significantly (Table II).

Blood gas and hematocrit measurements. Blood gas and hematocrit measurements are shown in Table II. Both groups started out in a somewhat alkalotic state at baseline, a phenomenon that we have seen in previous animal studies. There was no significant difference between groups and, over time, in $\mathrm{pH}$ and $\mathrm{PCO}_{2}$ levels; particular care was taken so that $\mathrm{pH}$ and $\mathrm{PCO}_{2}$ would be in the normal physiologic range $\left(\mathrm{pH} 7.35-7.45 ; \mathrm{PCO}_{2}\right.$, $35-45 \mathrm{~mm} \mathrm{Hg}$ ) when fluorescent microspheres were injected at the designated time points. The hematocrit levels decreased as expected during cooling in both groups but returned to baseline at the end of CPB. 


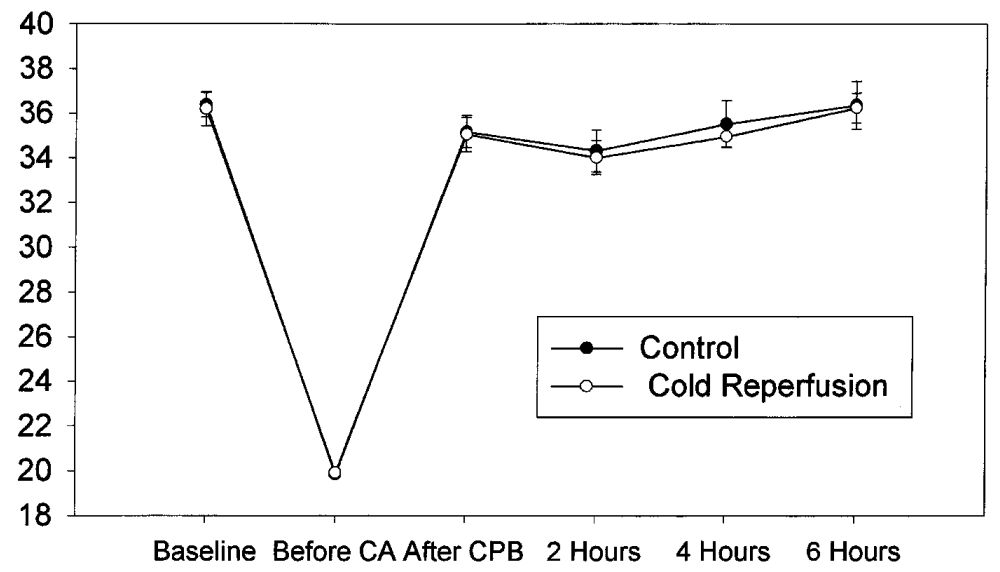

Fig 1. Direct measurement of deep brain temperatures in animals after 90 minutes of HCA and standard rewarming (control) or cold reperfusion (mean values $\pm \mathrm{SD})$. $C A$, Circulatory arrest.

Table I. Esophageal, epidural, and rectal temperature in 16 pigs undergoing 90 minutes of HCA followed by either standard rewarming (control) or cold reperfusion (CR)

\begin{tabular}{|c|c|c|c|c|c|c|c|}
\hline Group & No. & $\begin{array}{c}\text { Baseline } \\
\left(37^{\circ}\right)\end{array}$ & $\begin{array}{c}\text { End of } C P B \\
\text { Cooling }\left(20^{\circ}\right)\end{array}$ & $\begin{array}{c}\text { After } C P B \\
\left(37^{\circ}\right)\end{array}$ & 2 Hours & 4 Hours & 6 Hours \\
\hline \multicolumn{8}{|c|}{ Esophageal temperature $\left({ }^{\circ} \mathrm{C}\right)$} \\
\hline Control & 8 & $36.3 \pm 0.4$ & $21.0 \pm 0.5$ & $35.0 \pm 0.9$ & $34.2 \pm 1.1$ & $35.5 \pm 1.1$ & $36.4 \pm 1.1$ \\
\hline $\mathrm{CR}$ & 8 & $36.0 \pm 0.5$ & $20.5 \pm 0.9$ & $33.9 \pm 1.0$ & $33.1 \pm 0.7$ & $34.2 \pm 0.8$ & $35.7 \pm 0.8$ \\
\hline \multicolumn{8}{|c|}{ Epidural temperature $\left({ }^{\circ} \mathrm{C}\right)$} \\
\hline Control & 8 & $35.9 \pm 0.2$ & $20.1 \pm 0.6$ & $34.7 \pm 0.9$ & $34.1 \pm 1.1$ & $35.1 \pm 0.9$ & $35.8 \pm 0.9$ \\
\hline CR & 8 & $35.7 \pm 0.4$ & $20.0 \pm 0.2$ & $34.8 \pm 0.8$ & $33.5 \pm 0.4$ & $34.7 \pm 0.6$ & $35.9 \pm 0.5$ \\
\hline \multicolumn{8}{|c|}{ Rectal temperature $\left({ }^{\circ} \mathrm{C}\right)$} \\
\hline Control & 8 & $36.8 \pm 0.5$ & $22.2 \pm 0.9$ & $34 \pm 1.3$ & $34.4 \pm 1.2$ & $35.9 \pm 1.1$ & $36.9 \pm 1$ \\
\hline $\mathrm{CR}$ & 8 & $36.4 \pm 0.7$ & $21.9 \pm 0.8$ & $33 \pm 0.8$ & $33.3 \pm 0.9$ & $34.2 \pm 0.8$ & $36.6 \pm 0.6$ \\
\hline
\end{tabular}

Values are shown as mean \pm standard deviation. No statistical significance was detected between groups in epidural temperature; esophageal and rectal temperature did differ significantly, but all values were within expected ranges.

CBF and cerebral metabolism. Table III displays CBF and cerebral oxygen consumption for the 2 experimental groups. CBF decreased with $\mathrm{CPB}$ cooling to $20^{\circ} \mathrm{C}$ in both groups. Although $\mathrm{CBF}$ appeared to recover somewhat faster in the control group, there were no significant differences between the groups at any of the time points, and CBF did not return to baseline values in either group until 6 hours after the start of reperfusion.

With regard to cerebral oxygen consumption, both groups showed a decrease, as expected, during cooling. There was still a decrease in cerebral oxygen consumption in both groups as late as 2 hours after the start of reperfusion, but metabolism had returned to baseline values in both groups by 4 hours, with no significant differences noted between the groups at any point.

Sagittal sinus lactate and oxygen saturation. Sagittal sinus lactate increased slightly in both groups during cooling (Table III). Lactate did not quite return to base- line levels even 6 hours after rewarming, confirming that anaerobic metabolism was occurring and that recovery of purely aerobic metabolism was still incomplete even after several hours. There were no significant differences in lactate accumulation between the groups at any time point, however.

Cerebral venous (sagittal sinus) oxygen saturations, as expected, increased in both groups after cooling, reflecting the markedly decreased demand for oxygen resulting from metabolic suppression (Table III). In both groups, the oxygen saturations returned almost to baseline values immediately after rewarming and stayed at these values until 2 hours after the start of reperfusion. However, then the oxygen saturations fell significantly below baseline values in the control group at $4(P=.005)$ and 6 hours $(P=.04)$, suggesting that increased oxygen extraction was needed to maintain optimal levels of metabolism in this group. This 
Table II. Hemodynamic data, blood gases, and hematocrit levels in 16 pigs undergoing 90 minutes of HCA followed by either standard rewarming (control) or cold reperfusion (CR)

\begin{tabular}{|c|c|c|c|c|c|c|c|c|}
\hline Group & No. & $\begin{array}{c}\text { Baseline } \\
\left(37^{\circ}\right)\end{array}$ & $\begin{array}{l}\text { End of } C P B \\
\text { cooling }\left(20^{\circ}\right)\end{array}$ & $\begin{array}{c}\text { After } C P B \\
\left(37^{\circ}\right)\end{array}$ & 2 Hours & 4 Hours & 6 Hours & $\mathrm{P}$ value \\
\hline \multicolumn{9}{|c|}{ MAP (mm Hg) } \\
\hline Control & 8 & $79.6 \pm 14$ & $50.6 \pm 1.2$ & $52.6 \pm 4.7$ & $49.6 \pm 1.9$ & $54.0 \pm 4.6$ & $53.1 \pm 2.6$ & \\
\hline $\mathrm{CR}$ & 8 & $74.0 \pm 13.3$ & $52.7 \pm 4$ & $52.1 \pm 2.7$ & $52.1 \pm 3.5$ & $56.0 \pm 3.1$ & $58.9 \pm 4.7$ & NS \\
\hline \multicolumn{9}{|c|}{ Cardiac output (L/min) } \\
\hline Control & 8 & $2.5 \pm 0.3$ & & $1.9 \pm 0.3$ & $2.2 \pm 0.3$ & $2.4 \pm 0.3$ & $2.5 \pm 0.3$ & \\
\hline $\mathrm{CR}$ & 8 & $2.8 \pm 0.1$ & & $2.1 \pm 0.04$ & $2.7 \pm 0.1$ & $2.8 \pm 0.1$ & $2.8 \pm 0.1$ & * \\
\hline \multicolumn{9}{|l|}{ Arterial $\mathrm{pH}$} \\
\hline Control & 8 & $7.5 \pm 0.03$ & $7.4 \pm 0.02$ & $7.4 \pm 0.04$ & $7.4 \pm 0.03$ & $7.4 \pm 0.03$ & $7.4 \pm 0.04$ & \\
\hline $\mathrm{CR}$ & 8 & $7.5 \pm 0.04$ & $7.4 \pm 0.02$ & $7.4 \pm 0.05$ & $7.4 \pm 0.05$ & $7.4 \pm 0.07$ & $7.4 \pm 0.08$ & NS \\
\hline \multicolumn{9}{|c|}{ Arterial $\mathrm{PCO}_{2}(\mathrm{~mm} \mathrm{Hg})$} \\
\hline Control & 8 & $41.7 \pm 2.3$ & $38.9 \pm 2.6$ & $40.4 \pm 2.9$ & $42.2 \pm 2.1$ & $41.0 \pm 3.4$ & $40.7 \pm 1.4$ & \\
\hline $\mathrm{CR}$ & 8 & $41.9 \pm 3.1$ & $38.7 \pm 2.6$ & $40.7 \pm 3.8$ & $40.9 \pm 3.0$ & $42.9 \pm 1.3$ & $41.6 \pm 2.9$ & NS \\
\hline \multicolumn{9}{|c|}{ Hematocrit (\%) } \\
\hline Control & 8 & $28.7 \pm 4.2$ & $21.5 \pm 0.9$ & $28.1 \pm 1.3$ & $27.5 \pm 2.3$ & $27.5 \pm 2.8$ & $25.1 \pm 3.4$ & \\
\hline $\mathrm{CR}$ & 8 & $28.4 \pm 2.4$ & $21.5 \pm 0.9$ & $29.5 \pm 3$ & $29.9 \pm 2.8$ & $30.2 \pm 3.2$ & $28.9 \pm 2.7$ & NS \\
\hline
\end{tabular}

Values are shown as mean \pm standard deviation. $M A P$, Mean arterial pressure; $\mathrm{PCO}_{2}$, carbon dioxide tension; $\mathrm{NS}$, not significant.

*There was a significant difference between groups in cardiac output, but that is due to differences in the baseline values; average differences between groups in change from baseline did not differ significantly.

Table III. Metabolic data in 16 pigs undergoing 90 minutes of HCA followed by either standard rewarming (control) or cold reperfusion (CR)

\begin{tabular}{|c|c|c|c|c|c|c|c|}
\hline Group & No. & $\begin{array}{c}\text { Baseline } \\
\left(37^{\circ}\right)\end{array}$ & $\begin{array}{l}\text { End of } C P B \\
\text { cooling }\left(20^{\circ}\right)\end{array}$ & $\begin{array}{c}\text { After } C P B \\
\left(37^{\circ}\right)\end{array}$ & 2 Hours & 4 Hours & 6 Hours \\
\hline \multicolumn{8}{|c|}{$\begin{array}{l}\text { Cerebral blood flow } \\
\qquad\left(\mathrm{mL} \cdot 100 \mathrm{~g}^{-1} \cdot \mathrm{min}^{-1}\right)\end{array}$} \\
\hline Control & 8 & $52.5 \pm 12.6$ & $22.3 \pm 8.1$ & $40.3 \pm 14.8$ & $30.4 \pm 10.3$ & $35.4 \pm 17.4$ & $45.4 \pm 17.5$ \\
\hline CR & 8 & $45.0 \pm 3.0$ & $23.3 \pm 3.7$ & $28.9 \pm 7.4$ & $24.3 \pm 8.6$ & $27.8 \pm 5.5$ & $41.3 \pm 7.7$ \\
\hline \multicolumn{8}{|c|}{$\begin{array}{l}\text { Cerebral oxygen consumption } \\
\left(\mathrm{mL} \cdot 100 \mathrm{~g}^{-1} \cdot \mathrm{min}^{-1}\right)\end{array}$} \\
\hline Control & 8 & $1.9 \pm 0.5$ & $0.3 \pm 0.1$ & $1.2 \pm 0.3$ & $1.1 \pm 0.2$ & $1.8 \pm 0.6$ & $2.0 \pm 1.1$ \\
\hline CR & 8 & $1.7 \pm 0.3$ & $0.3 \pm 0.1$ & $1.3 \pm 0.5$ & $1.2 \pm 0.3$ & $1.4 \pm 0.3$ & $1.8 \pm 0.6$ \\
\hline \multicolumn{8}{|c|}{ Sagittal sinus lactate $(\mathrm{mmol} / \mathrm{L})$} \\
\hline Control & 8 & $1.4 \pm 0.4$ & $3.1 \pm 0.8$ & $8.0 \pm 3.0$ & $7.4 \pm 2.7$ & $6.2 \pm 3.1$ & $5.2 \pm 4.0$ \\
\hline $\mathrm{CR}$ & 8 & $1.7 \pm 0.8$ & $2.8 \pm 0.5$ & $7.3 \pm 3.4$ & $6.9 \pm 3.3$ & $6.3 \pm 3.5$ & $5.2 \pm 3.7$ \\
\hline \multicolumn{8}{|c|}{ Sagittal sinus oxygen $(\%)$} \\
\hline Control & 8 & $80.6 \pm 3.4$ & $90.9 \pm 3.2$ & $77.5 \pm 9.8$ & $78.5 \pm 7.8$ & $66.3 \pm 10.3$ & $67.6 \pm 15$ \\
\hline $\mathrm{CR}$ & 8 & $76.4 \pm 7.2$ & $92.9 \pm 4.2$ & $70.8 \pm 14.8$ & $72.3 \pm 11.3$ & $72.4 \pm 7.6$ & $73.9 \pm 8.3$ \\
\hline
\end{tabular}

Values are shown as mean \pm standard deviation. No statistical significance was detected between groups.

implies that $\mathrm{CBF}$ in the control group, although not significantly different from CBF after cold reperfusion, was nevertheless inadequate for the metabolic recovery of the brain in the late recovery period.

ICP. As depicted in Table IV, ICP stayed almost at baseline values during cooling. After rewarming, a sustained increase in ICP occurred in the control group, but not in animals with cold reperfusion. There were statistically significant differences between groups in the absolute values of ICP $(P=.004)$ and in the changes from values at the end of cooling at $20^{\circ} \mathrm{C}(P=.03)$.
Histopathologic results. Fig 2 shows the histopathologic score, arrived at by assessment of histopathologic findings in the neocortex of the brain for each of the animals. As is evident from the graph, few animals had major histopathologic abnormalities after 90 minutes of HCA, and a simple comparison of the incidence of histopathologic lesions showed no significant difference between control animals and those with cold reperfusion.

However, if all animals with a high ICP were compared with those without cerebral edema, there was a 
Table IV. ICP in 16 pigs undergoing 90 minutes of HCA followed by either standard rewarming (control) or cold reperfusion $(C R)$

\begin{tabular}{|c|c|c|c|c|c|c|c|}
\hline Group & No. & $\begin{array}{c}\text { Baseline } \\
\left(37^{\circ}\right)\end{array}$ & $\begin{array}{l}\text { End of } C P B \\
\text { cooling }\left(20^{\circ}\right)\end{array}$ & $\begin{array}{c}\text { After } C P B \\
\left(37^{\circ}\right)\end{array}$ & 2 Hours & 4 Hours & 6 Hours \\
\hline Control & 8 & $11.8 \pm 2.5$ & $9.9 \pm 2.5$ & $13 \pm 3.3$ & $14.4 \pm 1.9$ & $15.4 \pm 3.1$ & $16.3 \pm 3.8$ \\
\hline $\mathrm{CR}$ & 8 & $10.3 \pm 1.9$ & $9.3 \pm 1.4$ & $9.3 \pm 1.4$ & $9.9 \pm 1.2$ & $11.4 \pm 1.7$ & $12.1 \pm 1.4$ \\
\hline
\end{tabular}

Values are shown as mean \pm standard deviation. $P=.004$ between groups in the absolute values; $P=.03$, changes from end of cooling.

Table V. Electrophysiologic recovery 6 hours after rewarming in 16 pigs undergoing 90 minutes of $\mathrm{HCA}$ followed by either standard rewarming (control) or cold reperfusion

\begin{tabular}{lcc}
\hline & Control & Cold reperfusion \\
\hline EEG & $7.3(0-23)$ & $6.8(4-24)$ \\
Cortical evoked potentials & $25.5(10.1-57.1)$ & $35.7(13.9-96.5)$ \\
Cervical evoked potentials & $88.1(45.8-163.7)$ & $68.3(64.8-86.4)$ \\
\hline
\end{tabular}

Values are expressed as median (range) percent of baseline. There was no statistically significant difference between groups (Wilcoxon rank sum test).

statistically significant correlation of high ICP with the occurrence of histopathologic abnormalities: such abnormalities were more likely to occur in the presence of a high ICP, and all animals with high ICPs were in the control group. All 3 animals that had an ICP of more than $15 \mathrm{~mm} \mathrm{Hg}$ had positive histopathologic results, and among those that had an ICP of less than 15 $\mathrm{mm} \mathrm{Hg}, 3$ had positive histopathologic results and 10 did not $(P=.04)$.

EEG and evoked potentials. No significant difference was observed between the experimental groups in recovery of EEG or in reappearance of cervical or cortical evoked potentials after 90 minutes of HCA. The degree of recovery of these various electrophysiologic parameters 6 hours after the start of reperfusion is shown in Table V. At earlier times very little recovery was seen, with no differences in the median recovery between experimental groups. The rapidity of recovery of electrophysiologic signals in this study is consistent with earlier observations, in which the cervical evoked potentials usually reappeared earliest and cortical somatosensory evoked potentials preceded reappearance of the EEG. The median values for recovery of cortical somatosensory evoked potentials in the cold reperfusion group were consistently slightly higher than in the controls (4 hours after rewarming: median $22.2 \%$ [10.1\%-38\%] in the control group vs $28.9 \%$ [0\%-46.3\%] in the cold reperfusion group; at 6 hours: median $25.5 \%$ [10.1\%-57.1\%] in the control group vs $35.7 \%$ [13.9\%-96.5\%] in the cold reperfusion group). This difference might have proven statistically significant if a larger number of animals had been tested. This observation is in accord with the other data suggesting that cold reperfusion may have a beneficial effect on recovery after prolonged HCA.

Brain water content. The percent of brain water calculated as described above showed no statistically significant difference between animals in the cold reperfusion and control groups: the median value was $79.05 \%(78.3 \%-79.9 \%)$ in the control group versus $78.6 \%(78.1 \%-80.5 \%)$ in the cold reperfused animals.

\section{Discussion}

As the use of HCA for surgery of aortic aneurysms and repair of congenital heart disease in infants has become more widespread and successful, concern about the incidence of cerebral sequelae has prompted a number of investigations, both experimental and clinical, with the goal of improving its implementation. ${ }^{6,7}$ These studies have illuminated some of the possible physiologic and pharmacologic mechanisms that may be involved in cerebral injury after HCA, have explored alternative strategies for cerebral protection during these technically difficult operations, and have focused on various aspects of implementation of HCA that may affect outcome. ${ }^{5,7-14}$ Despite these efforts, the detailed mechanisms by which cerebral injury occurs after HCA are still unclear, as is the time course of the resulting damage. Several lines of evidence suggest that at least some of the injury may occur during reperfusion, raising the possibility that the extent of the damage may be subject to modification by variations in reperfusion strategy. ${ }^{15-17}$

One of the observations that has emerged from physiologic studies is that CBF often decreases after HCA. ${ }^{1-3,7,18-22}$ Since the fall in CBF is not always matched by a concomitant decrease in cerebral metabolism, it is often accompanied by an increase in cerebral venous desaturation, reflecting an increase in oxygen extraction. ${ }^{7,17,23,24}$ This inappropriate rise in cerebral vascular resistance, seen consistently several hours after the 
start of reperfusion in studies in weanling puppies, ${ }^{25}$ seems to correspond to observations in infants of decreased transcranial Doppler flow velocities in the middle cerebral artery after HCA and absence of flow during diastole. ${ }^{1-3,20,21}$ This phenomenon has raised concern about a possible compromise in oxygen delivery during the vulnerable interval during which the brain is trying to recover from the ischemic insult posed by HCA. ${ }^{8,26,27}$ Therefore, the observation by 2 investigators that an interval of cold reperfusion seemed to improve transcranial Doppler flow patterns in infants after HCA, and its subsequent confirmation in a prospective study, seemed to warrant further exploration. ${ }^{1-3}$

It has been suggested that the mechanism of the postoperative decrease in $\mathrm{CBF}$ after HCA, especially the absence of flow during diastole, might be related to the development of cerebral edema after HCA. ${ }^{20}$ Several investigators have observed an increase in ICP in infants after HCA. ${ }^{22,28}$ In the course of exploring hypothermic retrograde perfusion as an alternative to HCA in pigs, we documented a consistent increase in direct measurements of ICP after HCA even in control animals that had not undergone retrograde cerebral perfusion (unpublished observations). The fact that there was a clear correlation between ICP and subsequent neurologic outcome-animals with a high intraoperative ICP during retrograde cerebral perfusion much more frequently exhibited subsequent cerebral histopathologic abnormalitiesprompted us to re-examine the possible significance of the less dramatic but nevertheless quite frequent rise in ICP seen after HCA in the context of this study of cold reperfusion.

The current study demonstrates that ICP after cold reperfusion after HCA is significantly lower than after conventional rewarming. In addition, a correlation exists between the presence of high ICP postoperatively and a poorer outcome histopathologically, even though a direct comparison of the animals in the cold reperfusion and control groups showed no significant difference in the incidence of histopathologic lesions. The fact that a direct comparison of the histopathologic scores does not show a better outcome after delayed rather than standard rewarming does not preclude the possibility that cold reperfusion may be of benefit: the magnitude of the effect may have been too small to have been detected in the few animals in each group in this study. It is also possible that the histopathologic comparison might have shown more dramatic differences had the animals been sacrificed later or if the tissues had been assessed for the possible presence of apoptosis, which has recently been suggested to play a role in neurotoxicity after HCA. ${ }^{29-31}$

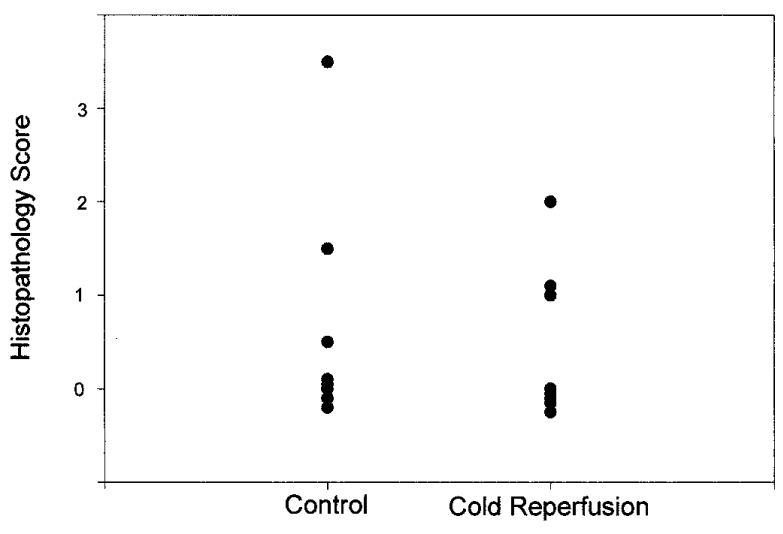

Fig 2. Occurrence of histopathologic lesions in pigs that underwent standard rewarming (control) versus those with an interval of cold reperfusion. Each circle represents a single animal. A score of zero indicates a complete absence of histopathologic abnormalities, and higher scores correspond to increasingly extensive evidence of cerebral injury as explained in detail in the text. There was no significant difference between the groups in the extent of histopathologic abnormalities.

When all the animals in both groups were taken together, there was a significantly greater incidence of cerebral histopathologic lesions in animals with a high ICP, all of which were in the control group. Whether the reduced ICP seen after delayed rewarming is a concomitant reflection of less severe cerebral injury after cold reperfusion or is actually part of the mechanism of its beneficial effect is not clear from this study or from previous studies. However, the consensus seems to be that less severe cerebral edema is a favorable prognostic sign, and therefore the unequivocal reduction of postoperative ICP with delayed rewarming in this study adds to the impetus for use of cold reperfusion as a way of minimizing cerebral injury after HCA.

We were surprised that median $\mathrm{CBF}$ was not significantly higher after cold reperfusion, especially in view of the higher ICP in the control group and the clinical reports of improved transcranial Doppler flow after delayed reperfusion. ${ }^{1-3}$ However, because sagittal sinus oxygen saturations in the cold reperfusion group returned to baseline levels early after HCA and remained high thereafter, in contrast to the control group, in which saturations fell significantly below baseline levels at 4 and 6 hours after the start of rewarming, we think that $\mathrm{CBF}$ was actually better after cold reperfusion than in the control pigs. The increased oxygen extraction in the control animals suggests the presence of a more severe degree of inappropriate cerebral vasoconstriction than occurred in the cold reperfusion group and a smaller margin of 
safety in terms of oxygen delivery. Thus, the oxygen saturation data, which imply indirectly that cerebral perfusion several hours postoperatively was better in the cold reperfusion group, contribute to the evidence that cold reperfusion may be helpful in allowing optimal recovery from HCA.

In theory, cold reperfusion would allow any toxic substances released by cerebral tissues rendered ischemic during HCA to be washed away before these noxious substances could elicit a self-destructive response from the vulnerable brain. It is conceivable that factors that might initiate apoptosis or cause glutamate toxicity could effectively be flushed from the brain during an interval of cold reperfusion while the brain remained too inert to respond..$^{13,29-31} \mathrm{We}$ speculate that once the cerebral environment has been cleansed of oxygen-derived free radicals, cytokines, and high levels of anaerobic metabolites such as lactate, and once acidosis has been corrected during cold reperfusion, it may be possible to repair ischemic injury gradually as the brain rewarms without triggering as many untoward consequences as are seen after immediate rewarming.

Although our previous animal studies have consistently demonstrated reactive hyperemia immediately after HCA using standard rewarming techniques, followed only later by decreases in CBF, others have reported cerebral hypoperfusion even during the period of rewarming, as well as later after HCA. ${ }^{1-3,18,22,27}$ Reduced perfusion in a warming brain may cause an imbalance between oxygen delivery and metabolic demands, leading to further ischemic damage during the critical period of recovery from HCA. ${ }^{16}$ On the basis of physiologic principles, it seems likely that gradual or stepwise rewarming would best preserve the balance between $\mathrm{CBF}$ and metabolism. In fact, there is evidence that rapid rewarming and postischemic hyperthermia are harmful to the brain. ${ }^{16,26}$ Reactive hyperemia, which often seems to occur with immediate rewarming after $\mathrm{HCA}^{25}$ - and is reflected by the high flow in the control group on reaching $37^{\circ} \mathrm{C}$ in this study-may also pose its own luxury perfusion-associated dangers: increased exposure to macroemboli and microemboli. The use of cold reperfusion seems a logical extension of the attempt to match CBF and metabolism both early and late postoperatively: to ensure not only that cerebral metabolism will not outstrip $\mathrm{CBF}$ during recovery from HCA, but also that CBF will not be excessive for metabolic needs.

Although the evidence that cold reperfusion may improve outcome after prolonged HCA is somewhat tenuous, it is also true that the possible adverse consequences of using this technique are minimal. We there- fore now use a short period of cold reperfusion in patients with prolonged HCA before rewarming, especially in infants. More clinical studies will be required to establish that this practice is unequivocally beneficial, and more laboratory investigations will be needed to elucidate the mechanism by which cold reperfusion improves cerebral recovery after HCA.

We thank Richard Smith, Richard Henry, and Russell Jenkins for invaluable technical assistance.

Received for publication May 4, 2000; revisions requested Aug 11, 2000; revisions received Oct 6, 2000; accepted for publication Nov 27, 2000.

Address for reprints: Randall B. Griepp, MD, Department of Cardiothoracic Surgery, Mount Sinai School of Medicine, One Gustave Levy Place, Box 1028, New York, NY 10029.

\section{REFERENCES}

1. Astudillo R, van der Linden J, Ekroth R, Wesslen O, Hallhagen $\mathrm{S}$, Scallan M, et al. Absent diastolic cerebral blood flow velocity after circulatory arrest but not after low flow in infants. Ann Thorac Surg 1993;56:515-9.

2. Jonassen AE, Quaegebeur JM, Young WL. Cerebral blood flow velocity in pediatric patients is reduced after cardiopulmonary bypass with profound hypothermia. J Thorac Cardiovasc Surg 1995;110:934-43.

3. Rodriguez RA, Austin EH, Audenaert SM. Postbypass effects of delayed rewarming on cerebral blood flow velocities in infants after total circulatory arrest. J Thorac Cardiovasc Surg 1995; 110:1686-91.

4. Mezrow CK, Midulla PS, Sadeghi AM, Gandsas A, Wang W, Dapunt OE, et al. Evaluation of cerebral metabolism and quantitative electroencephalography after hypothermic circulatory arrest and low-flow cardiopulmonary bypass at different temperatures. J Thorac Cardiovasc Surg 1994;107:1006-19.

5. Juvonen T, Weisz DJ, Wolfe D, Zhang N, Bodian CA, McCullough JN, et al. Can retrograde cerebral perfusion mitigate cerebral injury after particulate embolization? A study in a chronic porcine model. J Thorac Cardiovasc Surg 1998;115:1142-59.

6. Griepp EB, Griepp RB. Cerebral consequences of hypothermic circulatory arrest in adults. J Card Surg 1992;7:134-54.

7. Mezrow CK, Sadeghi AM, Gandsas A, Dapunt OE, Shiang HH, Zappulla RA, et al. Cerebral effects of low-flow cardiopulmonary bypass and hypothermic circulatory arrest. Ann Thorac Surg 1994;57:532-9.

8. Mezrow CK, Sadeghi AM, Gandsas A, Dapunt OE, Shiang HH, Zappulla RA, et al. A vulnerable interval for cerebral injury: comparison of hypothermic circulatory arrest and low-flow cardiopulmonary bypass. Cardiol Young 1993;3:287-98.

9. Midulla PS, Gandsas A, Sadeghi AM, Mezrow CK, Yerlioglu ME, Wang W, et al. Comparison of retrograde cerebral perfusion to antegrade cerebral perfusion and hypothermic circulatory arrest in a chronic porcine model. J Card Surg 1994;9:560-74.

10. Ergin MA, Galla JD, Lansman SL, Quintana C, Bodian C, Griepp RB. Hypothermic circulatory arrest in operations on the thoracic aorta: determinants of operative mortality and neurologic outcome. J Thorac Cardiovasc Surg 1994;107:788-97. 
11. Ergin MA, Uysal S, Reich DL, Apaydin A, Lansman SL, McCullough JN, et al. Temporary neurological dysfunction after deep hypothermic circulatory arrest: a clinical marker of longterm functional deficit. Ann Thorac Surg 1999;67:1887-90.

12. Reich DL, Uysal S, Sliwinski M, Ergin MA, Kahn RA, Konstadt $\mathrm{SN}$, et al. Neuropsychologic outcome after deep hypothermic circulatory arrest in adults. J Thorac Cardiovasc Surg 1999;117: 156-63.

13. Baumgartner WA, Walinsky PL, Salazar JD, Tseng EE, Brock MV, Doty JR, et al. Assessing the impact of cerebral injury after cardiac surgery: Will determining the mechanism reduce the injury? Ann Thorac Surg 1999;67:1871-3.

14. Jonas RA. Hypothermia, circulatory arrest, and the pediatric brain. J Cardiovasc Anesth 1996;10:66-74.

15. Tseng EE, Brock MV, Kwon CC, Annanata M, Lange MS, Troncoso JC, et al. Increased intracerebral excitatory amino acids and nitric oxide after hypothermic circulatory arrest. Ann Thorac Surg 1999;67:371-6.

16. Shum-Tim D, Nagashima M, Shinoka T, Bucerius J, Nollert G, Lidov HG, et al. Postischemic hyperthermia exacerbates neurologic injury after deep hypothermic circulatory arrest. J Thorac Cardiovasc Surg 1998;116:780-92.

17. O'Rourke MM, Nork KM, Kurth CD. Altered brain oxygen extraction with hypoxia and hypotension following deep hypothermic circulatory arrest. Acta Neurochir 1997;(suppl)70:78-9.

18. Greeley WJ, Ungerleider RM, Smith LR, Reves JG. The effects of deep hypothermic cardiopulmonary bypass and total circulatory arrest on cerebral blood flow in infants and children. J Thorac Cardiovasc Surg 1989;97:737-45.

19. Hillier SC, Burrows FA, Bissonnette B, Taylor RH. Cerebral hemodynamics in neonates and infants undergoing cardiopulmonary bypass and profound hypothermic circulatory arrest: assessment by transcranial Doppler sonography. Anesth Analg 1991;72:723-8

20. van der Linden J. Cerebral hemodynamics after low-flow versus no-flow procedures. Ann Thorac Surg 1995;59:1321-5.

21. Ekroth R, van der Linden J, Lincoln C, Scallan M. Cerebral perfusion and metabolism after profound hypothermia-comparison between procedures involving no flow and low flow. Cardiol Young 1993;3:378-82.

22. O'Hare B, Bissonnette B, Bohn D, Cox P, Williams W. Persistent low cerebral blood flow velocity following profoundly hypothermic circulatory arrest in infants. Can J Anaesth 1995;42:964-71.

23. Greeley WJ, Kern FH, Ungerleider RM, Boyd JL 3d, Quill T, Smith LR, et al. The effect of hypothermic cardiopulmonary bypass and total circulatory arrest on cerebral metabolism in neonates, children, and children. J Thorac Cardiovasc Surg 1991;101:783-94.

24. van der Linden J, Astudillo R, Ekroth R, Scallan M, Lincoln C. Cerebral lactate release after circulatory arrest but not after low flow in pediatric heart operations. Ann Thorac Surg 1993; 56:1485-9.

25. Mezrow CK, Sadeghi AM, Gandsas A, Shiang HH, Levy D, Green R, et al. Cerebral blood flow and metabolism in hypothermic circulatory arrest. Ann Thorac Surg 1992;54:609-15.

26. van der Linden J, Ekroth R, Lincoln C, Pugsley W, Scallan M, Tyden H. Is cerebral blood flow/metabolic mismatch during rewarming a risk factor after profound hypothermic procedures in small children? Eur J Cardiothorac Surg 1989;3:209-15.
27. Pesonen EJ, Peltola KI, Korpela RE, Sairanen HI, Leijala MA, Raivio KO, et al. Delayed impairment of cerebral oxygenation after deep hypothermic arrest in children. Ann Thorac Surg 1999;67:1765-70.

28. Burrows FA, Hillier SC, McLeod ME, Iron KS, Taylor MJ. Anterior fontanel pressure and visual evoked potentials in neonates and infants undergoing profound hypothermic circulatory arrest. Anesthesiology 1990;73:632-6.

29. Tseng EE, Brock MV, Lange MS, Blue ME, Troncoso JC, Kwon $\mathrm{CC}$, et al. Neuronal nitric oxide synthesis inhibition reduces neuronal apoptosis after hypothermic circulatory arrest. Ann Thorac Surg 1997;64:1639-47.

30. Tseng EE, Brock MV, Lange MS, Troncoso JC, Blue ME, Lwenstein CJ, et al. Monosialoganglioside GM1 inhibits neurotoxicity after hypothermic circulatory arrest. Surgery 1998;124: 298-306.

31. Kurth CD, Priestley M, Golden J, McCann J, Raghupathi R. Regional patterns of neuronal death after deep hypothermic circulatory arrest in newborn pigs. J Thorac Cardiovasc Surg 1999; 118:1068-77.

\section{Discussion}

Dr Tatu S. Juvonen (Oulu, Finland). I have a couple of questions. You concluded that cold reperfusion may decrease cerebral edema, but you failed to demonstrate any difference in terms of brain weight between the groups during postmortem examination. Are there any discrepancies with this?

Second, did you consider performing these studies in a surviving porcine model? I believe you selected an acute model to run CBF studies, but did you pay too heavy a toll for this? In a chronic model you are able to get more accurate histopathologic data. I have some experience with this particular model and have learned that it is very difficult to find ischemic lesions shortly after CPB. However, if animals survive 7 days, those lesions are clearly seen.

My final questions concern your histopathologic protocol. What kind of fixation protocol did you use-formalin perfusion fixation? Did you evaluate apoptosis, which is currently very popular in this field?

Dr Ehrlich. Thank you very much for your comments. With regard to the histopathologic studies, we used formalin as a fixative, and we did not evaluate apoptosis, although we plan to do so in future studies.

The major drawback to using microspheres to determine $\mathrm{CBF}$ is that the study must be done in an acute model; the first 6 hours after reperfusion are of the most interest. I strongly agree that long-term studies should also be done to see the neurobehavioral score in these animals and to better evaluate histopathologic damage.

With regard to brain weight, although brain weight tended to be higher in the reperfusion group, the difference was not statistically significant. However, the numbers in this study are very small, and I think further studies must be done to determine whether cold reperfusion may have a beneficial effect. 